Case Report

\title{
Laparoscopic Repair of Right Paraduodenal Hernia in Adult Patients: Case Report and Literature Review
}

\author{
Tomoko Takagishi (D), Yuta Niimi, Goshi Matsuki, Shinta Nagano, Junsuke Hinami, \\ Masaaki Kajiwara, Kiyoshi Kaneko, Yoshihiro Kubota, and Osamu Nakai
}

Department of Surgery, Uji Tokushukai Medical Center, Uji, Kyoto 611-0041, Japan

Correspondence should be addressed to Tomoko Takagishi; tomokobe0502@gmail.com

Received 9 April 2018; Accepted 27 June 2018; Published 15 October 2018

Academic Editor: Gregorio Santori

Copyright (c) 2018 Tomoko Takagishi et al. This is an open access article distributed under the Creative Commons Attribution License, which permits unrestricted use, distribution, and reproduction in any medium, provided the original work is properly cited.

\begin{abstract}
A 56-year-old Japanese female presented with vomiting, nausea, and abdominal pain after excessive drinking and eating. Abdominal computed tomography showed an encapsulated circumscribed cluster of jejunal loops in the right upper quadrant. She was diagnosed with a strangulated intestinal obstruction caused by right paraduodenal hernia (PDH) and underwent an emergency laparoscopic repair. A view through the endoscope showed the right PDH, which was encapsulated under the mesocolon. Most of the small bowel was entrapped and adhered inside the sac, requiring careful adhesiolysis. The hernia orifice was expanded to a sufficient degree, and the strangulation was relieved, avoiding the need of resecting the small intestine. Recovery was uneventful, and the patient remains free of symptoms 3 years after surgery. Findings in a total of 29 patients (including this report) who underwent laparoscopic repair of right or left PDHs in Japan are discussed.
\end{abstract}

\section{Introduction}

Recognizing late-onset complications of congenital intestinal malrotation in adult patients is important [1]. Paraduodenal hernia (PDH) is the most common type of intra-abdominal hernia associated with congenital errors of rotation of the midgut, in which duodenal recesses, particularly paraduodenal recess, play a role [2]. PDH accounts for $53 \%$ of internal hernias, but only $0.2 \%$ to $5.8 \%$ of intestinal obstructions, and occurs in both adults and children [3]. Patients with PDH present with various symptoms, including those of acute or chronic obstruction and intermittent abdominal pain associated with nausea and vomiting [1], and some patients may present with a history of recurrent intestinal obstruction since childhood [4]. Two variants of $\mathrm{PDH}$ are known, right-sided and left-sided, with the latter being more common. Surgical repair of PDH has shifted dramatically from open laparotomy to laparoscopic procedures [5]. The clinical features of right-sided PDH have been described [4, 6-8], and advances in laparoscopic surgical techniques have permitted the safe and effective laparoscopic treatment of right-sided
PDH [4, 6-13]. This report describes the successful laparoscopic repair of a right-sided PDH in an adult patient. This study also reviews Japanese experiences with laparoscopic repair of PDH, comparing clinical features and surgical results in adult patients with right- or left-sided PDH.

\section{Case Report}

A 56-year-old Japanese female was referred to our hospital for vomiting, nausea, and abdominal pain after excessive drinking and eating. Abdominal pain occurred 6 hours after her last meal, followed 2 hours later by frequent vomiting. On admission, she was alert, afebrile, $160 \mathrm{~cm}$ in height, and $57.2 \mathrm{~kg}$ in weight. Her blood pressure (BP) was 158/ $95 \mathrm{mmHg}$, her heart rate (HR) was $80 / \mathrm{min}$, and her oxygen blood saturation (SpO2) was 100\% (room air). Physically, she complained of pain in the swollen right upper quadrant but without muscular defense. Her previous history included an oophorectomy for ovarian cysts at age 26 years, conservative treatment for duodenal ulcer at age 36 years, lithotripsy for ureter stones at age 48 years, and conservative 


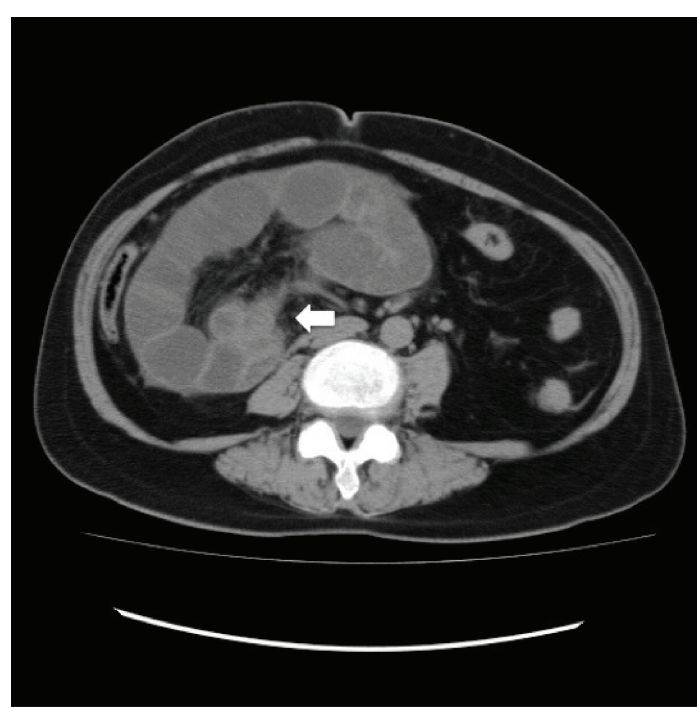

(a)

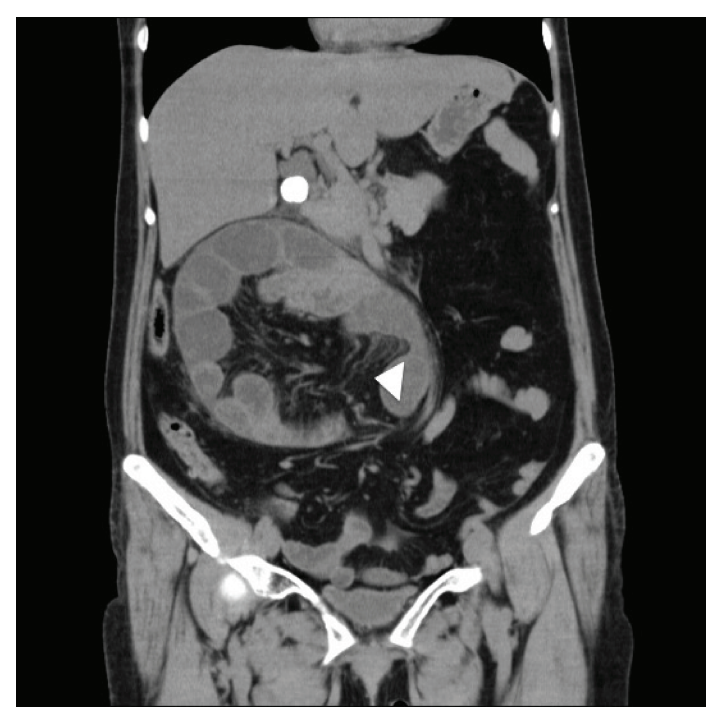

(b)

Figure 1: Abdominal CT (noncontrast-enhanced) findings in this patient. (a) Axial image showing that most of the small intestine was located in the right upper abdominal cavity and had a sac-like appearance (arrow). Ascites was observed within the sac. (b) Coronal image showing absence of the ligament of Treitz in the duodenum, along with a flattened inferior vena cava and distorted mesenteric veins (arrowhead). A $2 \mathrm{~cm}$-sized gallstone was also observed.

treatment for gallstones and cholecystitis at age 53 years. Laboratory data on admission included a white blood cell (WBC) count of $18,500 / \mu \mathrm{L}$, hemoglobin $(\mathrm{Hb})$ concentration of $16.0 \mathrm{~g} / \mathrm{dL}$, platelet count of $308 \times 10^{3} / \mu \mathrm{L}$, serum C-reactive protein (CRP) concentration of $1.06 \mathrm{mg} / \mathrm{dL}$, and lactate dehydrogenase concentration of $204 \mathrm{U} / \mathrm{L}$, with normal hepatic and renal function. Serum electrolyte levels were all within normal ranges. Abdominal computed tomography (CT) showed that most of the small intestine was located in the right upper abdominal cavity and had a sac-like appearance, without ligament of Treitz being present in the duodenum. CT of the vascular system showed a flattened inferior vena cava in association with edematous mesenterium and dilated mesenteric veins, findings suggesting a strangulated ileus (Figures 1(a) and 1(b)).

Emergency laparoscopic repair was performed. Under general anesthesia, a cut was made at the umbilicus, a $12 \mathrm{~mm}$ port was inserted using the open method, and $5 \mathrm{~mm}$ ports were inserted into the right and left lateral abdomen as well as the lower abdomen. Laparoscopic observation showed that the ascending and descending colons were in their normal positions, with the cecum in the right lower abdomen. However, ascites and distention of the small intestine were observed under the mesenteric membrane of the ascending colon. The duodenum showed a leftward and then a rightward bending, with most of the small intestine, except for a 1-meter-long section of the ileum in the ileocecal region, being packed within the ligament of Ladd, which formed a hernia sac (Figure 2). Although the small intestine was tightly adhesive within the hernia sac, careful peeling and incision release were performed without complications. The absence of severe ischemia within the incarcerated intestine precluded the need for intestinal resection. The patient's clinical course of postlaparoscopic repair was uneventful; she was

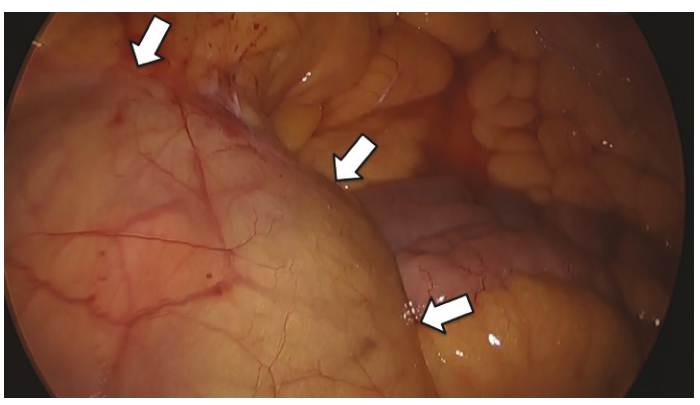

Figure 2: Photograph showing laparoscopic findings during surgery of the distended small intestine and ascites under the ascending mesocolon.

able to drink water on day 2 and was discharged on day 9 . Examination of an abdominal CT image of this patient taken at age 48 years showed a similar sac-like appearance, suggesting that this patient may have had intermittent $\mathrm{PDH}$ for 8 years. A follow-up CT scan after 2 months of surgical repair showed no abnormalities. At the time of writing, 3 years after surgical repair, the patient remains well without any recurrent symptoms or other complaints.

2.1. Literature Review. A survey of the ICHUSHI (Igaku Chuo Zasshi; the Japan Medical Abstract Society; http:// www.jamas.or.jp) of patients in Japan who underwent laparoscopic repair of PDH during the period of 2002 to 2017, using the keywords $\mathrm{PDH}$, laparoscopy, and adults ( $>18$ years old), identified 26 such patients in 22 studies, all written in Japanese [14-35] and two more patients in two studies written in English $[12,36]$. Including the present patient, a total of 29 patients were analyzed. The median age of these 29 patients was 52.3 years (range, 20-80 years), and the male 
TABLE 1: Characteristics of adult (>18 years) patients in Japan who underwent laparoscopic repair of right or left PDH.

\begin{tabular}{|c|c|c|c|}
\hline & $\begin{array}{l}\text { All } \\
29\end{array}$ & $\begin{array}{c}\text { Right } \\
8\end{array}$ & $\begin{array}{c}\text { Left } \\
21\end{array}$ \\
\hline Age (years), median (range) & $52.3(20-80)$ & $56(23-80)$ & $50(20-80)$ \\
\hline Male/female ratio & $16 / 13$ & $4 / 4$ & $12 / 9$ \\
\hline \multicolumn{4}{|l|}{ Symptoms } \\
\hline Abdominal pain & 25 & 8 & 17 \\
\hline Nausea/vomiting & 16 & 6 & 10 \\
\hline Abdominal distention & 3 & 0 & 3 \\
\hline Constipation/other* & 2 & 0 & 2 \\
\hline \multicolumn{4}{|l|}{ Time from initial symptoms to diagnosis } \\
\hline Early (<24 hours/1-7 days/7 days -3 months) & $5 / 5 / 3$ & $2 / 3 / 0$ & $3 / 2 / 3$ \\
\hline Late (3 months-1 year/>1 year/not described) & $2 / 11 / 3$ & $0 / 3 / 0$ & $2 / 8 / 3$ \\
\hline \multicolumn{4}{|l|}{ Timing of surgery } \\
\hline Emergency & 16 & 6 & 10 \\
\hline Elective & 11 & 2 & 9 \\
\hline Not described & 2 & 0 & 2 \\
\hline \multicolumn{4}{|l|}{ Surgical methods } \\
\hline Total laparoscopy & 22 & 7 & 15 \\
\hline Laparoscopy plus minilaparotomy & 3 & 0 & 3 \\
\hline Laparotomy migration & 4 & 1 & 3 \\
\hline \multicolumn{4}{|l|}{ Laparoscopic procedures } \\
\hline Closure of hernial orifice & 21 & 2 & 19 \\
\hline Release of hernia sac & 8 & 6 & 2 \\
\hline \multicolumn{4}{|l|}{ Outcome } \\
\hline Complete recovery & 22 & 6 & 16 \\
\hline Postoperative conservative treatment for intestinal obstruction & 5 & 1 & 4 \\
\hline Second operation needed & 2 & 1 & 1 \\
\hline
\end{tabular}

PDH: paraduodenal hernia. * Including one patient simultaneously diagnosed with inguinal hernia and PDH.

to female ratio was $16 / 13$. Eight patients had right-sided PDH while 21 had left-sided PDH. Their clinical features and laparoscopic repair results are shown in Table 1. Time from initial symptoms to diagnosis did not differ significantly between right and left-sided PDH. Emergency surgery was more frequent in patients with right-sided $\mathrm{PDH}$. Additional procedures during laparoscopic repair were more frequent in patients with left-sided (6/21) than right-sided (1/8) $\mathrm{PDH}$. Release of the hernia sac was more frequent in patients with right-sided PDH. Overall results were excellent, but a few patients with either right-sided or left-sided PDHs required additional postoperative care.

\section{Discussion}

PDHs are congenital mesocolic hernias caused by an abnormal rotation of the primitive midgut in embryonic life [11]. In cases of right $\mathrm{PDH}$, the counterclockwise rotation of the midgut is arrested on the right side. As a result, the small bowel becomes trapped in a hernial sac formed by the peritoneum behind the colonic mesentery, where the cecum and ascending colon rotate anteriorly, while in left $\mathrm{PDH}$, the small bowel invaginates into an avascular segment of the left mesocolon and is entrapped between the mesocolon and the posterior abdominal wall, forming the anterior wall of the hernia sac $[4,37]$.

This report describes an adult patient with right-sided $\mathrm{PDH}$, which was successfully managed by laparoscopic repair. Since right-sided PDH is rare and is frequently accompanied by nonspecific clinical signs, it was reported that laparoscopy may be necessary to confirm the precise diagnosis [8]. However, in this case, we confirmed the diagnosis preoperatively with use of abdominal CT findings.

In the diagnosis of $\mathrm{PDH}$, the symptoms and physical findings are vague and nonspecific, and plain abdominal radiographs and ultrasonography are also frequently nondiagnostic. Thus, the employment of abdominal CT is very helpful for the correct diagnosis. In fact, accurate preoperative diagnosis of $\mathrm{PDH}$ can be made by multidetector CT, which can detect the encapsulation of small bowel loops in the right midabdomen with looping of arterial and venous jejunal branches behind the superior mesenteric artery in right $\mathrm{PDH}$ and the encapsulation of bowel loops at or above the level of the ligament of Treitz with intermittent dilatation in left PDH [38].Contrast-enhanced CT may also be required for an accurate diagnosis of PDH [11].

$\mathrm{PDH}$ can be repaired by reduction of hernia contents and excision of the hernia sac, with or without intestinal 
derotation, thereby avoiding injury to the major mesenteric vessels juxtaposed to the hernial orifice. In the past, $\mathrm{PDH}$ was managed using laparoscopy or an open procedure $[7,8,10]$. However, a comparison of these two methods found that laparoscopy provided a more accurate preoperative diagnosis of $\mathrm{PDH}$, as well as good postoperative outcomes, including shorter hospital stay and shorter times to first flatus and to first intake of a soft diet [10]. Good exposure of the operative field is critical to successful laparoscopic repair procedures [5]. Fundamentally, laparoscopic surgery does not differ for right- and left-sided $\mathrm{PDH}$. However, right $\mathrm{PDH}$ is often associated with malrotation of the midgut and is sometimes complicated by strangulation, requiring division of the lateral attachments of the ascending colon with retraction to the left to reduce the size of the small bowel $[39,40]$. By contrast, left-sided $\mathrm{PDH}$ can be reduced manually without much difficulty. More difficulties were therefore encountered in patients with rightsided $\mathrm{PDH}$, as these patients require widening of the hernial orifice or division of the inferior mesenteric vein, as well as reduction of the invaginated intestine and suture closure of the hernial orifice $[39,41]$. In some patients, the inferior mesenteric vein may have to be sacrificed to facilitate reduction of the hernia contents [42].

Our literature review of 29 Japanese patients matched a previously reported incidence of right $(8 / 29 ; 27.6 \%)$ and left $(21 / 29 ; 72.4 \%)$ PDH. The findings of early (13/29) and late $(16 / 29)$ surgical interventions were also not significantly different from previous studies. It was noted that emergency surgery was more frequent in patients with right-sided $\mathrm{PDH}$. In the review, we focused particularly on the patients who were technically difficult, who required additional surgical procedures during the laparoscopic repair of $\mathrm{PDH}$. We found that such cases were more frequent in left-sided $\mathrm{PDH}$, of which three experienced difficulties in peeling severe adhesions, one had a significantly distended bowel, and one required intestinal resection for necrosis. In addition, two patients showed involvement of the inferior mesenteric vein at the hernial orifice, requiring open laparotomy due to their high risk of damage to blood vessels. Recent advances in laparoscopic procedures is thought generally to have resulted in excellent outcomes of PDH repair, although several patients have required additional procedures.

In summary, early and correct diagnosis is essential to avoid intestinal obstruction and strangulation due to $\mathrm{PDH}$ in adult patients. Laparoscopic procedures can expedite diagnosis and repair by obtaining a clear view of anatomical malrotation. Currently, for any symptomatic cases with PDH, either right or left-sided, less invasive laparoscopic approach can be safely carried out without the risk of complications under the condition where sufficient skills and the suitable equipments are available. However, in technically difficult cases, it is recommended not to cling on laparoscopy but to switch to open surgery.

\section{Conflicts of Interest}

The authors declare that they have no conflicts of interest.

\section{Acknowledgments}

The authors thank Dr. Shinsaku Imashuku for his assistance in preparing this manuscript.

\section{References}

[1] D. W. Dietz, R. M. Walsh, S. Grundfest-Broniatowski, I. C. Lavery, V. W. Fazio, and D. P. Vogt, "Intestinal malrotation: a rare but important cause of bowel obstruction in adults," Diseases of the Colon and Rectum, vol. 45, no. 10, pp. 1381-1386, 2002.

[2] S. V. Tambe, K. K. Rana, A. Kakar et al., "Clinical importance of duodenal recesses with special reference to internal hernias," Archives of Medical Science, vol. 13, no. 1, pp. 148-156, 2017.

[3] M. A. Khan, A. Y. Lo, and D. M. Vande Maele, "Paraduodenal hernia," The American Surgeon, vol. 64, no. 12, pp. 1218-1222, 1998.

[4] R. Mehra and A. K. Pujahari, "Right paraduodenal hernia: report of two cases and review of literature," Gastroenterology Report, vol. 4, no. 2, pp. 168-171, 2016.

[5] T. Uematsu, H. Kitamura, M. Iwase et al., "Laparoscopic repair of a paraduodenal hernia," Surgical Endoscopy, vol. 12, no. 1, pp. 50-52, 1998.

[6] C. M. Nuño-Guzmán, J. Arróniz-Jáuregui, C. HernándezGonzález et al., "Right paraduodenal hernia in an adult patient: diagnostic approach and surgical management," Case Reports in Gastroenterology, vol. 5, no. 2, pp. 479-486, 2011.

[7] S. Manfredelli, Z. Andrea, P. Stefano et al., "Rare small bowel obstruction: right paraduodenal hernia. Case report," International Journal of Surgery Case Reports, vol. 4, no. 4, pp. 412-415, 2013.

[8] E. Erdas, A. Pitzalis, D. Scano, S. Licheri, M. Pomata, and G. Farina, "Diagnosis and treatment of symptomatic right paraduodenal hernia: report of a case," Surgery Today, vol. 44, no. 1, pp. 192-196, 2014.

[9] E. Antedomenico, N. N. Singh, S. M. Zagorski, K. Dwyer, and M. H. Chung, "Laparoscopic repair of a right paraduodenal hernia," Surgical Endoscopy, vol. 18, no. 1, pp. 165-166, 2004.

[10] G. A. Jeong, G. S. Cho, H. C. Kim, E. J. Shin, and O. P. Song, "Laparoscopic repair of paraduodenal hernia: comparison with conventional open repair," Surgical Laparoscopy, Endoscopy \& Percutaneous Techniques, vol. 18, no. 6, pp. 611-615, 2008.

[11] J. G. Bittner 4th, M. A. Edwards, S. J. Harrison, K. Li, P. N. Karmin, and J. D. Mellinger, "Laparoscopic repair of a right paraduodenal hernia," Journal of the Society of Laparoendoscopic Surgeons, vol. 13, no. 2, pp. 242-249, 2009.

[12] T. Tomino, S. Itoh, D. Yoshida et al., "Right paraduodenal hernia successfully treated with laparoscopic surgery," Asian Journal of Endoscopic Surgery, vol. 8, no. 1, pp. 87-90, 2015.

[13] M. Ong, M. Roberts, M. Perera, and C. Pretorius, "Case of a strangulated right paraduodenal fossa hernia in a malrotated gut," BMJ Case Reports, 2017.

[14] C. Nakanishi, K. Mitsui, H. Matsumoto et al., "Two cases of left paraduodenal hernia - laparotomy and laparoscopic repair," Nihon Rinsho Geka Gakkai Zasshi (Journal of Japan Surgical Association), vol. 63, no. 5, pp. 1302-1307, 2002.

[15] M. Yamamoto, T. Yamaguchi, H. Takahashi, R. Takeda, and S. Sakata, "A case of left paraduodenal hernia diagnosed 
preoperatively and treated by laparoscopy-assisted surgery," Nihon Rinsho Geka Gakkai Zasshi (Journal of Japan Surgical Association), vol. 66, no. 9, pp. 2173-2176, 2005.

[16] M. Fukueda, K. Honbou, H. Futawatari, D. Yotsumoto, T. Misaka, and K. Fujisaki, "A case of left duodenal hernia successfully treated with laparoscopic surgery," Rinsho Zasshi Geka, vol. 67, no. 4, pp. 491-494, 2005.

[17] T. Takayama, S. Yamagata, S. Hamamoto, Y. Sato, T. Suzuki, and W. Takiyama, "A case of left paraduodenal hernia," The Journal of the Hiroshima Medical Association, vol. 57, no. 11, pp. 890-893, 2004.

[18] Y. Kakimoto, T. Yagi, S. Kuratate, T. Matsumura, and R. Fujino, "The left paraduodenal hernia cases diagnosed preoperatively and treated laparoscopically," The Journal of the Japanese Surgical Association, vol. 69, no. 11, pp. 2883-2886, 2008.

[19] H. Kamei, N. Murakami, M. Fujishita, K. Koufuji, K. Shirouzu, and S. Aoyagi, "Two cases of left paraduodenal hernia diagnosed preoperatively by MD-CT and operated laparoscopically," The Journal of the Japanese Surgical Association, vol. 69, no. 5, pp. 1263-1268, 2008.

[20] M. Fukushima and S. Fukuda, "Laparoscopic surgery for intestinal malrotation: report of the two cases," Journal of Japan Society for Endoscopic Surgery, vol. 14, no. 6, pp. 711-716, 2009.

[21] T. Takagi, Y. Nakase, K. Fukumoto, and T. Miyagaki, "Laparoscopic repair of paraduodenal hernia; a case report," Journal of Japan Society for Endoscopic Surgery, vol. 15, no. 3, pp. 373$378,2010$.

[22] T. Shikano, T. Kinoshita, M. Shibata, A. Yarita, S. Tokunaga, and S. Umeda, "A case of paraduodenal hernia with progressive gallbladder cancer diagnosed preoperatively and treated laparoscopic surgery," Rinsho Zasshi Shujutu, vol. 65, no. 13, pp. 1959-1961, 2011.

[23] Y. Kimura, K. Iwakawa, M. Nishie, Y. Tsunemitsu, M. Inagaki, and H. Iwagaki, "Six cases of internal hernia," Nihon Rinsho Geka Gakkai Zasshi (Journal of Japan Surgical Association), vol. 73, no. 8, pp. 2121-2126, 2012.

[24] T. Hamada, E. Taniguchi, K. Ohta, M. Yoshikawa, Y. Yamagami, and S. Ohashi, "Successful laparoscopic management for asymptomatic but preoperatively diagnosed paraduodenal hernia - a case report," The Journal of the Japanese Surgical Association, vol. 74, no. 2, pp. 396-399, 2013.

[25] Y. Moriyoshi, K. Tazawa, Y. Tsuchiya, H. Kojima, F. Yamagishi, and K. Tsukada, "A case of mesenterium communae with ileus caused by a band," Rinsho Zasshi Geka, vol. 75, no. 7, pp. 784-787, 2013.

[26] K. Sakamoto, Y. Yamaguchi, N. Kataoka, M. Tomita, M. Shinbo, and S. Makimoto, "A case of left paraduodenal hernia treated by laparoscopic surgery," Rinsho Zasshi Geka, vol. 75, no. 5, pp. 536-539, 2013.

[27] K. Okuyama, T. Tanaka, M. Tanaka, Y. Hirohashi, and S. Sato, "A case of left paraduodenal hernia preoperatively diagnosed by multi-detector CT," Nihon Rinsho Geka Gakkai Zasshi (Journal of Japan Surgical Association), vol. 74, no. 7, pp. 1856-1860, 2013.

[28] Y. Takanashi, J. Isogaki, T. Okumura, K. Yamashita, K. Suzuki, and A. Kawabe, "A case of right paraduodenal hernia in which a small bowel penetrated the hernia sac had prolapsed into the abdominal cavity," Nihon Rinsho Geka Gakkai Zasshi (Journal of Japan Surgical Association), vol. 75, no. 5, pp. 1433-1436, 2014.
[29] M. Amiki, T. Koike, R. Imaizumi, N. Kawano, and H. Honda, "A case of left paraduodenal hernia diagnosed preoperatively by MD-CT and operated laparoscopically," The Journal of the Saitama Medical Society, vol. 48, no. 2, pp. 407-411, 2014.

[30] A. Hayata, M. Hattori, K. Ando, A. Ogawa, and K. Ikuta, "A case of laparoscopic surgery for ileus of a paraduodenal hernia," Rinsho Zasshi Geka, vol. 78, no. 3, pp. 323-327, 2016.

[31] S. Nagayoshi, T. Adachi, M. Hisanaga et al., "Case report; two cases of left paraduodenal hernia diagnosed preoperatively by enhanced CT and operated laparoscopically," Nagasaki Igakkai Zasshi, vol. 90, no. 1, pp. 54-58, 2015.

[32] Y. Okazaki, I. Ooshima, K. Shinotou, and M. Ozaki, "A case of a left paraduodenal hernia treated laparoscopically," Japanese Society for Abdominal Emergency Medicine, vol. 36, no. 1, pp. 111-114, 2016.

[33] Y. Tokuda, M. Wakabayashi, K. Sasaki, and K. Kohno, "A case of paraduodenal hernia treated with laparoscopic assisted surgery," Japanese Society for Abdominal Emergency Medicine, vol. 35, no. 7, pp. 935-938, 2015.

[34] K. Inada, M. Hiyoshi, K. Nasu, Y. Nishihara, T. Maeshiro, and Y. Miyamoto, "A case of left paraduodenal hernia with superior mesenteric syndrome treated by laparoscopy surgery," Rinsho Zasshi Geka, vol. 79, no. 1, pp. 91-94, 2017.

[35] S. Kawata, K. Inaba, A. Fukazawa et al., "Laparoscopic operation for right paraduodenal hernia with intestinal malrotation in adult: report of a case," Nihon Gekakei Rengo Gakkaishi (Journal of Japanese College of Surgeons), vol. 41, no. 4, pp. 593-599, 2016.

[36] S. Uchiyama, N. Imamura, H. Hidaka et al., "An unusual variant of a left paraduodenal hernia diagnosed and treated by laparoscopic surgery: report of a case," Surgery Today, vol. 39, no. 6, pp. 533-535, 2009.

[37] K. I. Hassani, Y. Aggouri, S. A. Iaalim, I. Toughrai, and K. Mazaz, "Left paraduodenal hernia: a rare cause of acute abdomen," Pan African Medical Journal, vol. 17, p. 230, 2014.

[38] D. Warshauer and M. Mauro, "CT diagnosis of Paraduodenal hernia," Gastrointestinal Radiology, vol. 17, no. 1, pp. 13-15, 1992.

[39] M. K. Bartlett, C. Wang, and W. H. Williams, "The surgical management of paraduodenal hernia," Annals of Surgery, vol. 168, no. 2, pp. 249-254, 1968.

[40] B. M. Willwerth, R. M. Zollinger Jr., and R. J. Izant Jr., "Congenital mesocolic (paraduodenal) hernia: embryologic basis of repair," American Journal of Surgery, vol. 128, no. 3, pp. 358-361, 1974.

[41] R. A. Brigham, W. F. Fallon, J. R. Saunders, J. W. Harmon, and J. C. d'Avis, "Paraduodenal hernia: diagnosis and surgical management," Surgery, vol. 96, no. 3, pp. 498-502, 1984.

[42] C. Palanivelu, M. Rangarajan, P. A. Jategaonkar, N. V. Anand, and K. Senthilkumar, "Laparoscopic management of paraduodenal hernias: mesh and mesh-less repairs. A report of four cases," Hernia, vol. 12, no. 6, pp. 649-653, 2008. 


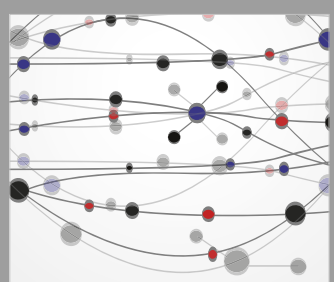

The Scientific World Journal
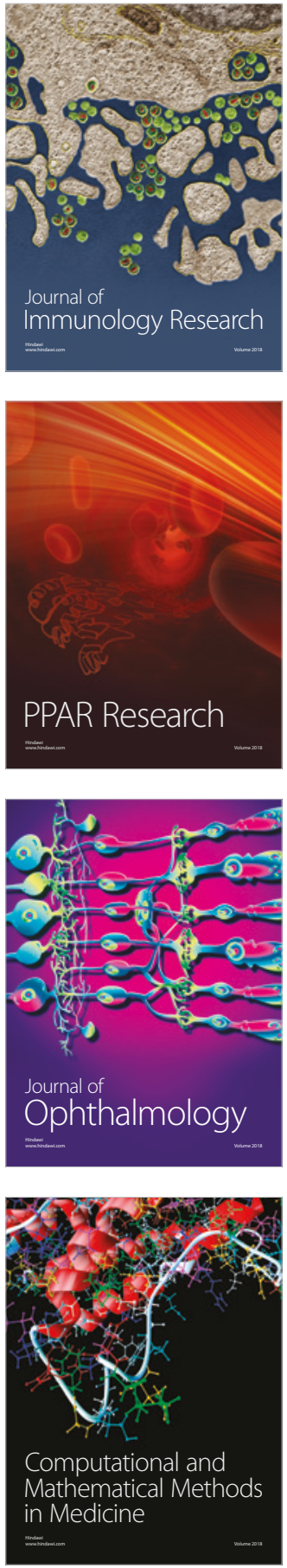

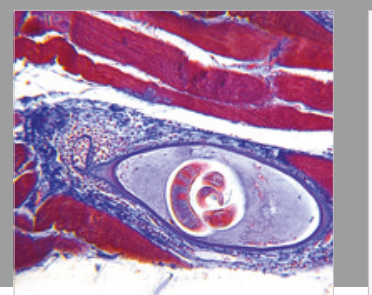

Gastroenterology Research and Practice

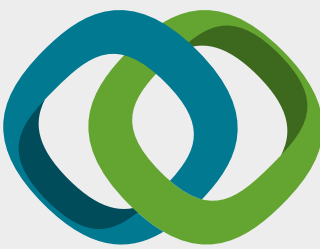

\section{Hindawi}

Submit your manuscripts at

www.hindawi.com
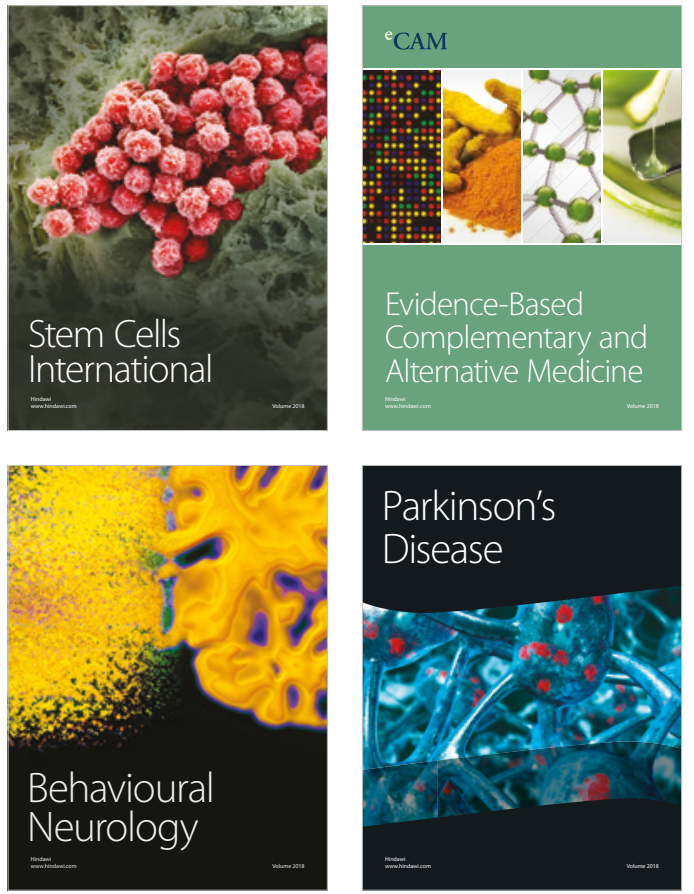

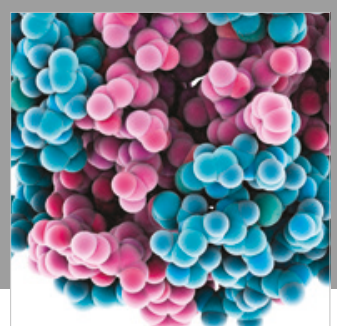

ournal of

Diabetes Research

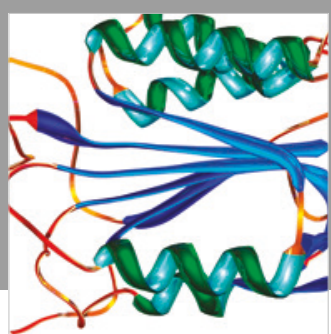

Disease Markers
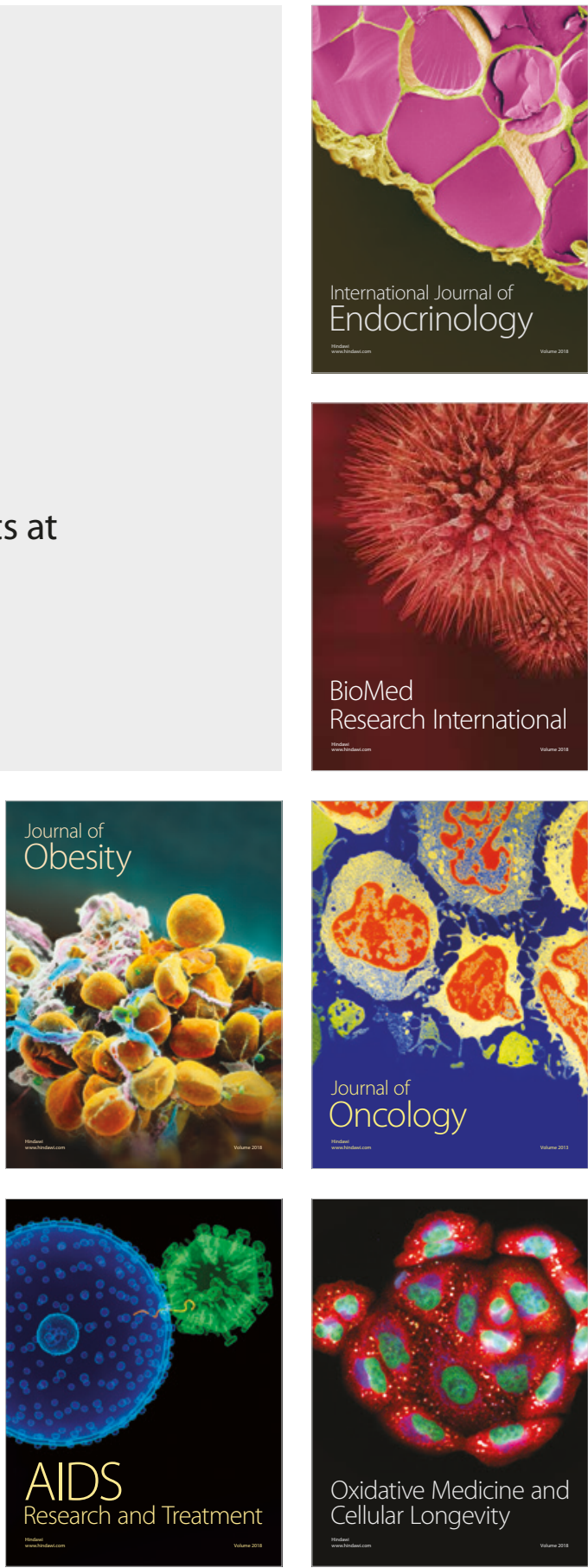